\title{
Effects of RU486 on the Interstitial Collagenase in the Process of Cervical Ripening in the Pregnant Rat
}

\author{
YUKIO IKUTA, KoHEI MATSUURA, Hitoshi OKAMURA, \\ IKUKO OYAMADA* AND GENTARO USUKU* \\ Department of Obstetrics and Gynecology, and *Department of \\ Developmental Biology, Institute for Medical Genetics, Kumamoto \\ University Medical School, Kumamoto 860, Japan
}

\begin{abstract}
Changes in interstitial collagenase activity in the rat uterine cervix during ripening were clarified in a time-dependent manner. Premature delivery was induced by an antiprogesterone agent, RU486, for rats in late pregnancy. The presence of interstitial collagenase in the extract from the rat cervical tissue was demonstrated, by sodium dodecyl sulfate (SDS)-polyacrylamide gel electrophoresis using the natural and unaffected collagen as a substrate. The collagenase activity was determined as the release of digested peptides from the radio-labeled collagen. Our experiments with RU486 were performed in rats on the 18th day of pregnancy. A single administration of RU486 $(15 \mathrm{mg} / \mathrm{kg}) \mathrm{resulted}$ in the premature delivery of all treated rats within $30 \mathrm{~h}$ after the injection (average time was $23.9 \mathrm{~h}$ ). The marked increase in cervical wet weight was observed up to the time to premature delivery along with a significant acceleration from $18 \mathrm{~h}$ after the adminsitration of RU486. In this state, the cervical collagenase activity was enhanced, the highest levels being recorded at $21 \mathrm{~h}$ after the administration. The interstitial collagenase in the uterine cervix appears to play a significant role in the regulation mechanisms of cervical ripening in late pregnant rats.
\end{abstract}

Key words: Interstitial collagenase, Cervical ripening, Premature delivery, Rat.

(Endocrinol Japon 38: 491-496, 1991)

THE UTERINE cervix in most species of animals is a firm and compact fibrous structure in the non-pregnant state. During pregnancy, the cervix tends to soften as a result of the morphologic and biochemical changes in the extracellular framework [1]. At term, with the appearance of some potent signals as triggers of the onset of labor and uterine contractions, progressive remodeling takes place rapidly in the uterine cervix.

There are numerous reports to date showing the effects of sex steroids [2,3], prostaglandins [4, 5], relaxin [6] and other factors [7] on the mechanisms of cervical softening and dilatation

Received: February 26, 1991

Accepted: August 20, 1991

Correspondence to: Dr. Yukio IKUTA, Department of Obstetrics and Gynecology, Kumamoto University Medical School, 2-2-1 Honjo, Kumamoto 860, Japan. being induced with drastic physical and/or biochemical changes in the extracellular structure $[8,9]$. On the other hand, there is evidence of a proteinase cascade on the mammalian collagenase as a key modulator of the degradation of connective tissue components in various conditions $[10,11]$.

Although a number of previous studies have shown that collagen breakdown in the cervical connective tissue plays a principal role in the process of cervical ripening and dilatation [12, 13], chronological observation has not yet been performed on the changes in cervical collagenase actively all through the period of cervical ripening and dilatation. Moreover, the existence of a true collagenase, which is able to cleave interstitial collagens into three quarter and one quarter fragments, was only recently demonstrated for the first time in the direct extract from the human 
cervical tissue during parturition [14].

The purpose of this study, therefore, is to show the presence of interstitial collagenase in the uterine cervix and to clarify the changes in the collagenase activity all through the progress of planned premature delivery in late pregnant rats. To induce premature labor, we used the antiprogesterone compound, RU486, the synthetic 19norsteroid which produces pronounced contraceptive and abortive effects in rodents.

\section{Materials and Methods}

\section{Preparation of the dilated cervices}

Virgin Wistar rats (9-12 w of age), weighing 190-230 g, were kept under a daily 12-h light schedule (07:00-19:00 h) with free access to food and water in a room at a constant temperature. Females and males were placed together on the night of proestrus. On the morning of Day 18 of pregnancy (Day 1 was defined as the day on which sperm was found in the vaginal smear), the rats were injected subcutaneously with either $70 \%$ ethanol vehicle or RU486 (17-hydroxy-11-[4dimethylaminophenyl]-17 [1-propynyl]oestra-4,9dien-3-one: Mifepristone: Roussel-Uclaf, Paris, France), (15 mg/kg) dissolved in vehicle. The time of premature delivery after RU486 administration was monitored. The onset of premature delivery was defined as the finding of the first pup in the vaginal inlet. RU486 of $15 \mathrm{mg} / \mathrm{kg}$ induced premature delivery 18 to $30 \mathrm{~h}$ after the injection (Fig. 1). However, a lesser amount $(10 \mathrm{mg} / \mathrm{kg})$ resulted in delivery about $30 \mathrm{~h}$ afterwards and a larger amount $(30 \mathrm{mg} / \mathrm{kg})$ yielded results similar to that of $15 \mathrm{mg} / \mathrm{kg}$. Therefore, $15 \mathrm{mg} / \mathrm{kg}$ was exclusively used in the present experiment. The rats were sacrificed by dislocation of cervical vertebrae at 0 , $8,12,16,18,21 \mathrm{~h}$ and intrapartum after RU486 treatment, and at $0,8,12,16,18,21$ and $24 \mathrm{~h}$ after vehicle injection. Because the average time from the RU administration to the onset of the premature delivery was $23.9 \mathrm{~h}$, the control experiment was performed for $24 \mathrm{~h}$. The cervices were removed at the bifurcation of the uterine horns, weighed and then immediately frozen at $-20^{\circ} \mathrm{C}$ in assay buffer (pH 7.5).

\section{Extraction of collagenase}

Collagenase was directly extracted from the uterine cervix by the method of Kishi \& Hayakawa [15] with a slight modification. The cervices from 9 to 19 rats were homogenized in 4 vol. of $0.25 \mathrm{M}$ sucrose. The homogenate was centrifuged at 9,000 $\mathrm{g}$ for $30 \mathrm{~min}$ at $4^{\circ} \mathrm{C}$, and the supernatant was collected [sucrose fraction 1]. The pellet was resuspended in 4 vol. of urea buffer ( $4 \mathrm{M}$ urea in $50 \mathrm{mM}$ Tris- $\mathrm{HCl}, \mathrm{pH} 7.5$ ) and centrifuged immediately at $9,000 \mathrm{~g}$ for $30 \mathrm{~min}$ at $4^{\circ} \mathrm{C}$ and the supernatant was again collected [urea fraction 1]. The urea extraction was then repeated twice in the same manner except for the difference in the length of the extraction period, that is $2 \mathrm{~h}$ and overnight, respectively [urea fractions 2 and 3]. Each fraction was dialyzed overnight against $3 \mathrm{M}$ KSCN in $40 \mathrm{mM}$ Tris- $\mathrm{HCl}$, containing $10 \mathrm{mM}$ $\mathrm{CaCl}_{2}, \mathrm{pH} 7.6$ and subsequently dialyzed overnight against the assay buffer $(50 \mathrm{mM}$ Tris-HCl, 5 $\mathrm{mM} \mathrm{CaCl}_{2}, 0.2 \mathrm{M} \mathrm{NaCl}$ and $\left.0.02 \% \mathrm{NaN}_{3}, \mathrm{pH} 7.5\right)$. The dialysate was centrifuged at $10,000 \mathrm{~g}$ for 30 $\min$ at $4^{\circ} \mathrm{C}$ to remove insoluble materials. Each supernatant was assayed individually for collagenase activity.

\section{Collagenase assay}

In vitro-labeled rat skin acid soluble type I collagen was prepared as the substrate according to the method of Cawston \& Barrett [16] with $\left[1-{ }^{14} \mathrm{C}\right]$ acetic anhydride (sp. act. $10 \mathrm{mCi} / \mathrm{mmole}$; ICN Radiochemicals, Irvine, CALIF, USA). Collagenase activity was measured by the method of Terato et al. [17] and was determined as the release of ${ }^{14} \mathrm{C}$-labeled peptide from the substrate in the solution $\left(7.0 \times 10^{4} \mathrm{cpm} / 200 \mu \mathrm{g}\right.$ labeled collagen/ tube) after incubating for $24 \mathrm{~h}$ at $30^{\circ} \mathrm{C}$. Activation of latent collagenase with trypsin (Sigma Chem. Co., St Louis, MO, USA) $(50 \mu \mathrm{g} / \mathrm{ml})$ was performed at $37^{\circ} \mathrm{C}$ for $10 \mathrm{~min}$ and then the mixture was treated with an excess of soybean trypsin inhibitor (Sigma Chem. CO., St Louis, MO, USA) $(200 \mu \mathrm{g} / \mathrm{ml}$; one $\mathrm{mg}$ inhibits approximately $1.8 \mathrm{mg}$ trypsin) for $20 \mathrm{~min}$ at room temperature. One unit of collagenase was defined as the activity by which $1 \mu \mathrm{g} / \mathrm{min}$ of in vitro-labeled collagen was hydrolyzed at $30^{\circ} \mathrm{C}$. In this study, collagenase activity was expressed as the sum of active, latent and total collagenase activity in each four fraction, and was described as the absolute activity per whole cervix.

\section{Electrophoresis}

To assess the collagen fragments digested by the 
collagenase, the enzyme solutions collected from each fraction were taken to $60 \%$ saturation with ammonium sulfate and fractionated on Sephadex G-200 (Pharmacia, Uppsala, Sweden) column (1.6 $\times 45 \mathrm{~cm})$ equilibrated and eluted with an assay buffer at a flow rate of $4 \mathrm{~m} / / \mathrm{h}$. Partially purified enzyme fractions were combined and concentrated by ultrafiltration (Collodion Bags) threefold to fourfold. Intact collagen $(600 \mu \mathrm{g})$ was digested for several days at $24^{\circ} \mathrm{C}$ with this concentrated sample. Subsequently the reaction mixtures were subjected to the SDS-polyacrylamide disc gel electrophoresis system of Hayashi et al. [18] with 7.5\% acrylamide gels, and staining was performed with $0.25 \%$ Coomassie Brilliant blue.

\section{Statistical analysis}

Results are shown as the mean \pm SD. Statistical comparisons were made by an unpaired Student's $t$-test.

\section{Results}

Antiprogesterone treatment of late pregnant rats

Figure 1 shows the distribution of the number of rats initiating premature delivery after RU486 treatment on Day 18 of pregnancy.

Premature delivery was induced in all rats from 18 to $30 \mathrm{~h}$ after the injection of RU486 $(15 \mathrm{mg} / \mathrm{kg}$ s.c.). The average time up to onset after the treatment was $23.9 \mathrm{~h}$. Between 21 and $24 \mathrm{~h}$, the highest number of rats went into premature delivery $(40 \%)$, and thereafter the number decreased. In our preliminary studies, the lesser amount of RU486 (10 mg/kg) had a tendency to delay initiation of premature delivery, which was induced in about $30 \mathrm{~h}$, and the larger amount (30 $\mathrm{mg} / \mathrm{kg}$ ) provoked delivery within a similar time interval to that with $15 \mathrm{mg} / \mathrm{kg}$ (data not shown).

Figure 2 demonstrates the time-dependent changes in cervical wet weight in the pregnant rats after RU486 or vehicle treatment.

The wet weight of the cervix on Day 18 of pregnancy increased greatly in comparison with that of the nonpregnant cervix $(p<0.005)$. There were no significant changes in the control group at $24 \mathrm{~h}$ after vehicle injection. In the rats treated with RU486, however, the cervical wet weight increased in a time dependent fashion, especially with a marked acceleration from $18 \mathrm{~h}$ after the adminis-

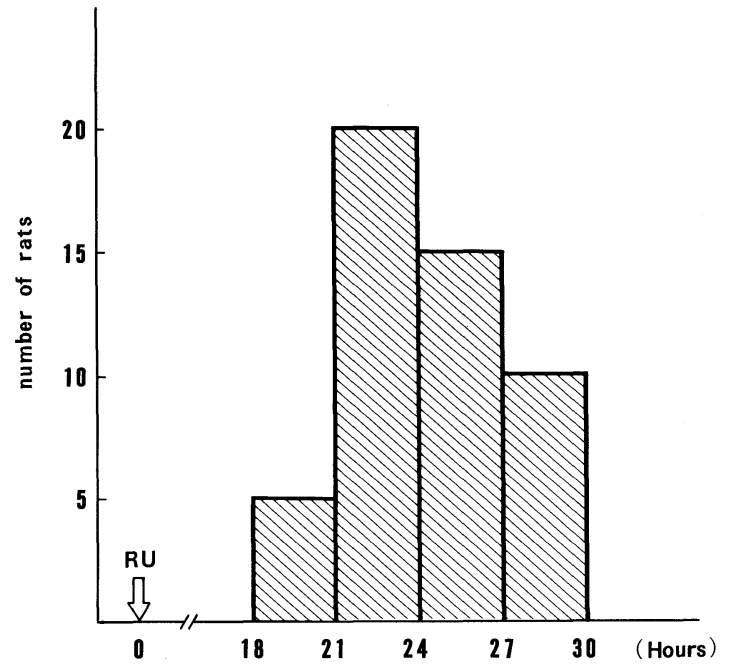

Fig. 1. The distribution of the number of rats corresponding to the onset time of premature delivery after a single subcutaneous injection of RU486 (15 mg/kg) on Day 18 of pregnancy.

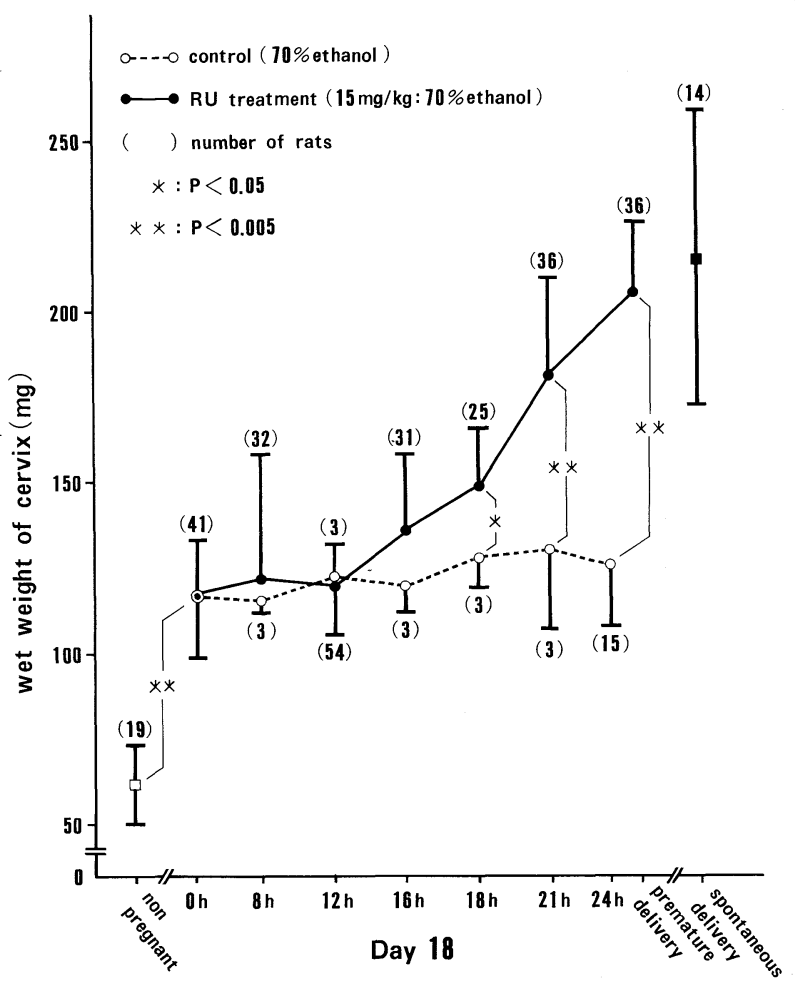

Fig. 2. Changes in wet weight of cervix in the control (open circle) and RU486-treated (closed circle) groups. Uterine cervices were collected at intervals as described in "Materials and Methods". Open and closed squares indicate the cervical wet weight of nonpregnant and spontaneous delivery groups, respectively. $*: \mathrm{p}<0.05, * *: \mathrm{p}<0.005$ compared with the corresponding groups. 


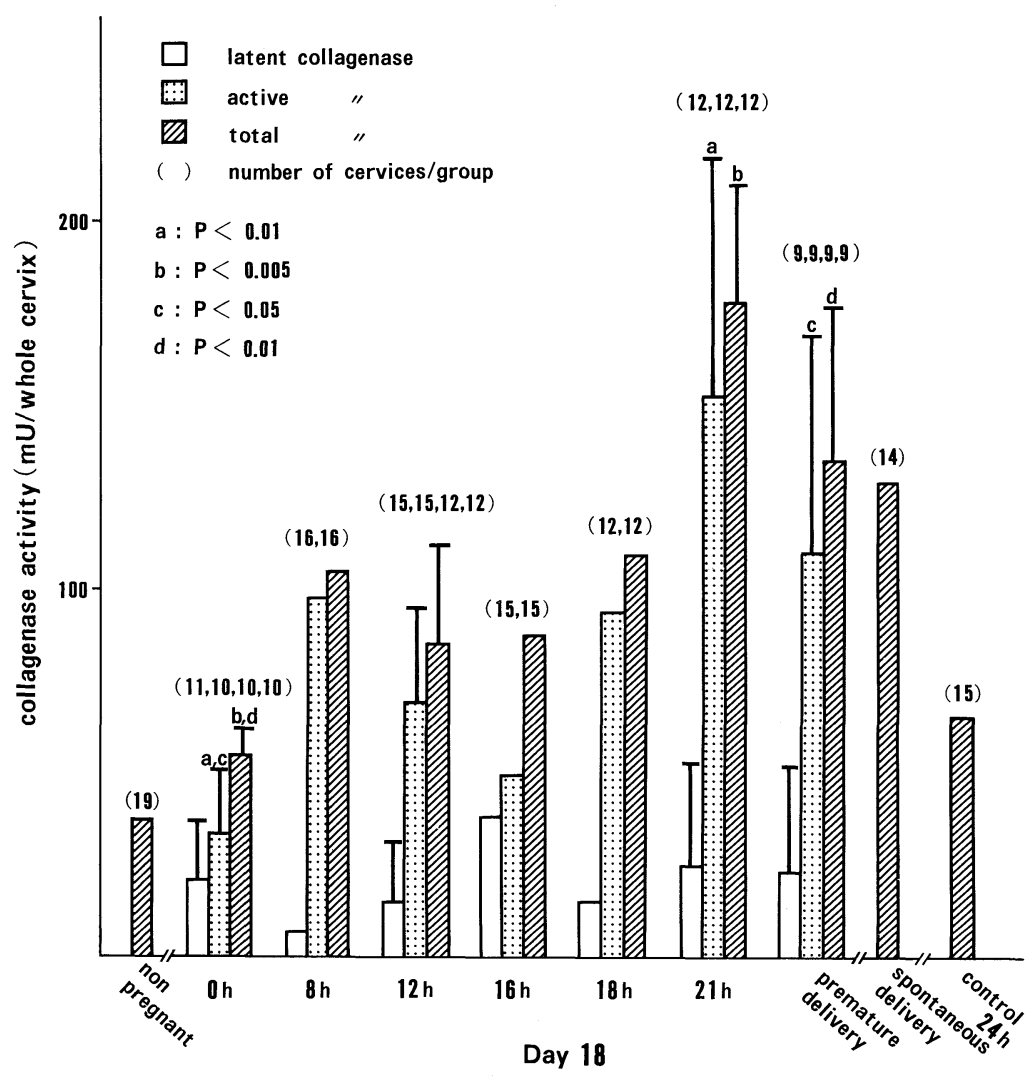

Fig. 3. The time course of interstitial collagenase activity in the process of cervical ripening directly demonstrated from the rat uterine cervix after RU486 treatment on Day 18 of pregnancy. In each group at $0,12,21 \mathrm{~h}$ and intrapartum after the treatment, the experiment for induction of premature labor was repeated three or four times using the numbers of rats indicated in the figure. The bars represent the mean \pm SD. $a, p<0.01$; $\mathrm{b}, \mathrm{p}<0.005 ; \mathrm{c}, \mathrm{p}<0.05 ; \mathrm{d}, \mathrm{p}<0.01$ compared with the corresponding groups.

tration, and was about 1.8 -fold at the time of premature delivery. The wet weight of the cervix at the time of spontaneous delivery was similar to that of premature delivery.

Identification of interstitial collagenase in the mechanisms of cervical ripening

Figure 3 shows the chronological change in interstitial collagenase activity from the rat uterine cervix in relation to the induction of premature delivery.

Total collagenase activity in the rat uterine cervix on Day 18 of pregnancy was 1.5 times as high as that in the non-pregnant cervix. Twentyone hours after the injection of RU486, both active and total collagenase activities reached their maximum values, i.e., 4.6- \& 3.2-fold potent compared with those just prior to the treatment $(\mathrm{p}<0.01$ and $\mathrm{p}<0.005)$. There are two peaks in the active form of collagenase at 8 and $21 \mathrm{~h}$ after the injection: the activity of the active form decreased from 8 to 16 $\mathrm{h}$, thereafter markedly increased to the highest level at $21 \mathrm{~h}$. Both active and total collagenase activities at the time of premature delivery were seen to be lower than those at $21 \mathrm{~h}$ (not significant). There were no remarkable changes in the control group at $24 \mathrm{~h}$ after vehicle injection.

EDTA and 1,10-phenanthrolin completely blocked this enzyme activity at the concentrations of $10 \mathrm{mM}$ and $1 \mathrm{mM}$. That is, in the treated group, the activities decreased to $2.3 \%$ and $0 \%$, respectively. Thus, the collagenolytic activity may belong to one of the metalloproteinases. Figure 4 shows the reaction products from enzymatic hydrolysis of collagen after incubation of collagen and the enzyme sample directly extracted from the rat 


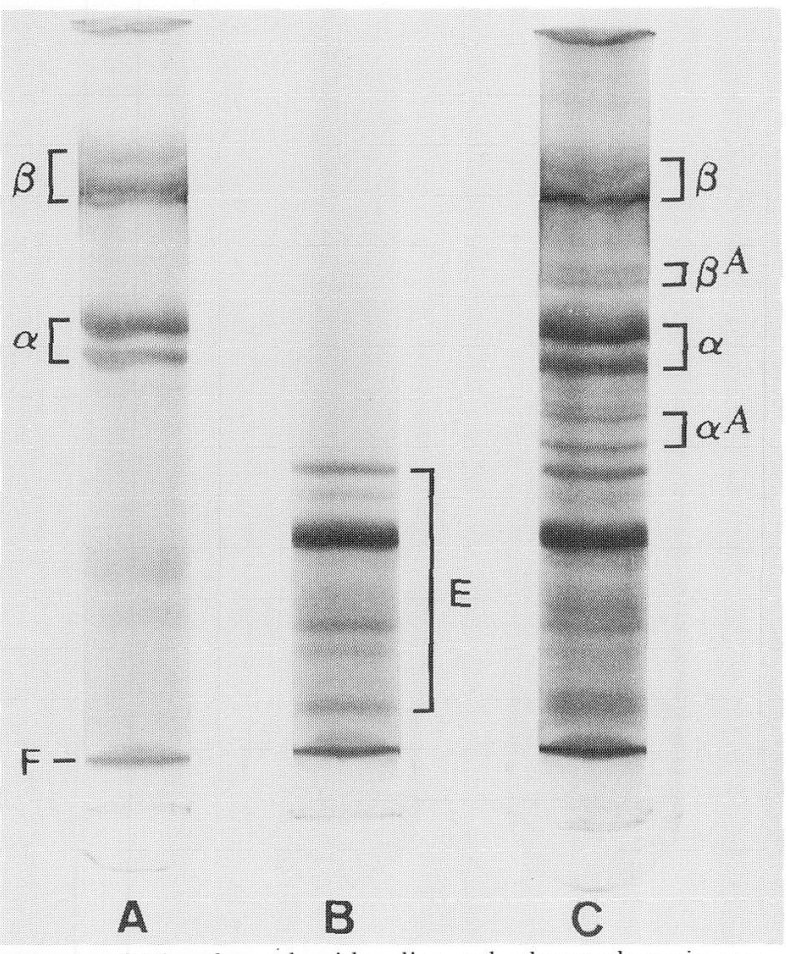

Fig. 4. SDS-polyacrylamide disc gel electrophoresis patterns of the digestion products of intact collagen molecules. The digestion of collagen and electrophoresis is described in "Materials and Methods". The major bands of collagen are $\beta$ (dimers), and $\alpha$ (monomers). The typical digestion fragments are labelled with an A superscript. A, control, rat skin acid soluble type I collagen; B, enzyme alone; C, type I collagen plus the enzyme sample. E shows protein bands derived from the enzyme sample. F denotes a buffer front.

uterine cervix after RU486 treatment. The appearance of digested fragments $\left(\alpha^{\mathrm{A}}\right.$ and $\beta^{\mathrm{A}}$ ) indicates the presence of interstitial collagenase in the enzyme sample.

\section{Discussion}

The present study showed that $15 \mathrm{mg} / \mathrm{kg}$ of RU486, a strong progesterone receptor antagonist, induced premature delivery within $30 \mathrm{~h}$ after the injection in all experimental rats $(9-12 \mathrm{w}$ of age) on Day 18 of pregnancy. We demonstrated, for the first time, the presence of interstitial collagenase from the rat cervical tissue by sodium dodecyl sulfate (SDS)-polyacrylamide gel electrophoresis of breakdown products of the substrate collagen. Moreover, for the first time, we chronologically observed the changes in collagenase activity in the rat cervix during its ripening.
It has been suggested that changes in the estrogen level, an increases in the estrogenprogesterone ratio or the appearance of other unknown factors in the cervix during pregnancy would trigger progressive cervical ripening and dilatation at term [19]. In the present study, the wet weight of the rat cervix increased rapidly from $18 \mathrm{~h}$ after RU486 treatment and was about 1.8-fold at the time of premature delivery (Fig. 2). With the changes in its wet weight, the interstitial collagenase activity in the cervix varied, recording the highest levels at $21 \mathrm{~h}$ after the treatment, shortly before the premature delivery. This finding appears to be compatible with the observation of Downing \& Sherwood [20] which showed a rapid breakdown of collagen in the rat uterine cervix shortly before term parturition on Day 22 of pregnancy. Several conditions in the uterine cervix, such as changes in its wet weight, the levels of some sex hormones and the activity of the interstitial collagenase, are possibly important in rapid and sufficient dilatation of the softened cervix for the passage of the conceptus on the initiation of premature delivery.

In cultures of post-partum rat uterus, the collagenase activity is inhibited by progesterone [22]. It has been shown that the action of RU486 is mediated through the progesterone receptor on preterm birth in the rat [23]. Accordingly, in our study it was speculated that the collagenase activity was expressed through the antiprogesterone effect of RU486 at the receptor level. Estrogens [3] and prostaglandins [21] are also involved in the mechanism of cervical dilatation, as possible factors in regulating the collagenase activity. However, we must further investigate the action and correlation of the possible factors which must have an effect on the control of the collagenase activity in the process of cervical ripening in order to fully understand this phenomenon.

Summing up the findings of the present study, it has been shown that interstitial collagenase plays an important role in the cervical ripening mechanism on the induction of premature delivery with RU486 in pregnant rats. Further investigations designed to assess the nature of other factors which are involved in collagen metabolism, such as tissue inhibitor of metalloproteinase [24, 25] and plasminogen activator, will provide more information on the mechanism of cervical ripening in pregnant rats. 


\section{References}

1. Danforth DN (1980) Early studies of the anatomy and physiology of the human cervix and implications for the future. In: Naftolin F, Stubblefield PG (eds) Dilatation of the Uterine Cervix: Connective Tissue Biology and Clinical Management. Raven Press, New York, 3-16.

2. Hollingsworth M, Isherwood CNM, Foster RW (1979) The effects of oestradiol benzoate, progesterone, relaxin and ovariectomy on cervical extensibility in the late pregnant rat. $J$ Reprod Fert 56 : 471-477.

3. Mochizuki M, Tojo S (1980) Effect of dehydroepiandrosterone sulfate on softening and dilatation of the uterine cervix in pregnant women. In: Naftolin F, Stubblefield PG (eds) Dilatation of the Uterine Cervix: Connective Tissue Biology and Clinical Management. Raven Press, New York, 267-286.

4. Williams LM, Hollingsworth M, Dukes M, Morris ID (1983) Fluprostenol-induced softening of the cervix of the pregnant rat. J Endocr 97: 283-290.

5. Ledger WL, Webster MA, the late Anderson ABM, Turnbull AC (1985) Effect of inhibition of prostaglandin synthesis on cervical softening and uterine activity during ovine parturition resulting from progesterone withdrawal induced by epostane. $J$ Endocr 105: 227-233.

6. Downing SJ, Sherwood OD (1985) The physiological role of relaxin in the pregnant rat. III. The influence of relaxin on cervical extensibility. Endocrinology 116: 1215-1220.

7. Ito A, Hiro D, Sakyo K, Mori Y (1987) The role of leukocyte factors on uterine cervical ripening and dilation. Biol Reprod 37: 511-517.

8. Golichowski AM, King SR, Mascaro K (1980) Pregnancy-related changes in rat cervical glycosaminoglycans. Biochem J 192: 1-8.

9. Williams LM, Hollingsworth M, Dixon JS (1982) Changes in the tensile properties and fine structure of the rat cervix in late pregnancy and during parturition. J Reprod Fert 66: 203-211.

10. Harris ED Jr., Welgus HG, Krane SM (1984) Regulation of the mammalian collagenases. Coll Rel Res 4: 493-512.

11. He C, Wilhelm SM, Pentland AP, Marmer BL, Grant GA, Eisen AZ, Goldberg GI (1989) Tissue cooperation in a proteolytic cascade activating human interstitial collagenase. Proc Natn Acad Sci USA 86: 2632-2636.

12. Kitamura K, Ito A, Mori Y, Hirakawa S (1979) Changes in the human uterine cervical collagenase with special reference to cervical ripening. Biochem Med 22: 332-338.
13. Uldbjerg N, Ekman G, Malmstrom A, Olsson K, Ulmsten U (1983) Ripening of the human uterine cervix related to changes in collagen, glycosaminoglycans and collagenolytic activity. Am J Obstet Gynecol 147: 662-666.

14. Rajabi MR, Dean DD, Beydoun SN, Woessner JF, Jr (1988) Elevated tissue levels of collagenase during dilation of uterine cervix in human parturition. Am J Obstet Gynecol 159: 971-976.

15. Kishi J, Hayakawa T (1982) Extraction of latenttype collagenase from cultured bovine dental pulps with $\mathrm{NaCl}$ or urea or by collagen degradation. Coll Rel Res 2: 301-311.

16. Cawston TE, Barrett AJ (1979) A rapid and reproducible assay for collagenase using $\left[1-{ }^{14} \mathrm{C}\right]$ acetylated collagen. Analyt Biochem 99: 340-345.

17. Terato K, Nagai Y, Kawanishi K, Yamamoto S (1976) A rapid assay method of collagenase activity using ${ }^{14}$ C-labeled soluble collagen as substrate. Biochim Biophys Acta 445: 753-762.

18. Hayashi T, Nagai Y (1979) Separation of the $\alpha$ chains of type I and III collagens by SDSpolyacrylamide gel electrophoresis. J Biochem 86: 453-459.

19. Huszar G, Naftolin F (1984) The myometrium and uterine cervix in normal and preterm labor. New Eng J Med 311: 571-581.

20. Downing SJ, Sherwood OD (1986) The physiological role of relaxin in the pregnant rat. IV. The influence of relaxin on cervical collagen and glycosaminoglycans. Endocrinology 118: 471-479.

21. Nimrod C, Currie J, Yee J, Dodd G, Persaud D (1984) Cervical ripening and labor induction with intracervical triacetin base prostaglandin $\mathrm{E}_{2}$ gel. Obstet Gynecol 64: 476-479.

22. Jeffrey JJ, Coffey RJ, Eisen AZ (1971) Studies on uterine collagenase in tissue culture. II. Effect of steroid hormones on enzyme production. Biochem Biophys Acta 252: 143-149.

23. Garfield RE, Gasc JM, Baulieu EE (1987) Effects of the antiprogesterone RU486 on preterm birth in the rat. Am J Obstet Gynecol 157: 1281-1285.

24. Curry TE, Jr, Dean DD, Koos RD, LeMaaire WJ (1986) A metalloprotease inhibitor in the rat ovary: changes in activity during the preovulatory period. Biol Reprod [Suppl 1] 34: 85.

25. Okada Y, Watanabe S, Nakanishi I, Kishi J, Hayakawa T, Watorek W, Travis J, Nagase $\mathrm{H}$ (1988) Inactivation of tissue inhibitor of metalloproteinases by neutrophil elastase and other serine proteinases. FEBS Lett 229: 157-160. 